\title{
A PRODUÇÃO CIENTÍFICA ACERCA DO ASPECTO TÁTICO-TÉCNICO NOS JOGOS ESPORTIVOS COLETIVOS: ANÁLISE DOS PERIÓDICOS BRASILEIROS
}

\author{
SCIENTIFIC PRODUCTION ON THE TACTICAL-TECHNICAL ASPECT IN TEAM \\ SPORTS: ANALYSIS OF BRAZILIAN JOURNALS \\ PRODUCCIÓN CIENTÍFICA SOBRE EL ASPECTO TÁCTICO-TÉCNICO EN
JUEGOS DEPORTIVOS COLECTIVOS: ANÁLISIS DE PERIÓDICOS BRASILENOS
}

Rodrigo Aquino*, Isabella S. Alves ${ }^{\star *}$, Maickel Bach Padilha*, Júlio Garganta*, Renato Francisco Rodrigues Marques ${ }^{* \star}$

\begin{abstract}
Palavras chave:
Produção

acadêmica.

Editoração.

Esportes.

Jogos.

Resumo: 0 objetivo do presente estudo foi analisar a produção científica referente aos aspectos tático-técnicos nos JEC publicada em periódicos brasileiros entre 2000 e 2015. Por meio da busca online em 14 revistas, foram selecionados 335 artigos. Os trabalhos foram classificados nas seguintes categorias temáticas: Análise do desempenho táticotécnico, Metodologias de ensino, Análise do desempenho energético-funcional, Formação de treinadores, Formação de atletas e Outros. A partir de 2009, verifica-se um aumento substancial no número de publicações. A maior frequência de publicações $(60,9 \%)$ encontra-se entre as temáticas Análise do desempenho tático-técnico e Metodologias de ensino. Adicionalmente, das 16 modalidades esportivas exibidas nos artigos, o futebol $\mathrm{e}$ o futsal contemplam 50,7\% das publicações. Conclui-se que a produção científica acerca dos aspectos tático-técnicos nos JEC ainda é pouco abrangente e plural, portanto, mais estudos são necessários, sobretudo na Formação de Treinadores e Atletas, assim como em modalidades esportivas coletivas para pessoas com deficiência.
\end{abstract}

\section{Keywords:}

Academic

production.

Publishing.

Sports.

Team Sports.

Palabras clave: Producción académica. Editorial. Deportes. Juegos.
Abstract: This study examined scientific production on tactical-technical aspects of team sports, published in Brazilian journals between 2000 and 2015. After an online search in 14 journals, 335 articles were selected and classified under the following thematic categories: Tactical-technical performance analysis; Teaching methodologies; Energy-functional performance analysis; Coach training; Athletes' training; and others. The number of publications has seen substantial increase since 2009. The higher frequencies of publications $(60.9 \%)$ are distributed among themes related to Tactical-technical performance analysis and Teaching methodologies. Additionally, of 16 sports presented in the articles, Football and Futsal accounted for $50.7 \%$ of publications. We found that scientific production related to tactical-technical aspects in team sports is still not comprehensive and plural. Therefore, more studies are needed, especially on Coach and Athletes' Training, as well as team sports for people with disabilities.

Resumen: El objetivo de este estudio fue analizar la producción científica sobre los aspectos técnicos y tácticos en los Juegos de Deportes Colectivos (JDC) en revistas brasileñas entre 2000 y 2015. A través de la búsqueda online en 14 revistas, fueron seleccionados 335 artículos. Los estudios fueron clasificados: Análisis del rendimiento técnico-táctico, Metodologías de enseñanza, Análisis de rendimiento funcional de energía, formación de entrenadores, Formación de atletas y otros. Desde 2009, ha habido un aumento sustancial en el número de publicaciones. La mayor frecuencia de publicaciones (60.9\%) se encuentra entre las temáticas: Análisis de rendimiento técnico-táctico y las Metodologías de enseñanza. Fútbol y Futbol de sala incluyen el $50.7 \%$ de las publicaciones. Se concluye que la producción científica sobre los aspectos tácticos y técnicos es incompleta, se necesitan, más estudios, especialmente en la formación de los entrenadores y atletas, así como en los deportes colectivos para las personas con discapacidad física.
*Universidade do Porto. Porto, Portugal. E-mail: rodrigo.aquino@usp.br; maickel.bpadilha@gmail.com; jgargant@fade.up.pt

**Universidade de São Paulo. São Paulo, SP, Brasil.

E-mail: santosalvesisabella@gmail.com; renatomarques@usp.br

Recebido em: 17-11-2016 Aprovado em: 27-10-2017

DOI:

http://dx.doi.org/10.22456/1982-8918.69461

(c) (1) (8) Licence 


\section{INTRODUÇÃO}

A produção do conhecimento científico em Educação Física/Ciências do Esporte no Brasil tem apresentado um crescimento vertiginoso nas últimas duas décadas, especialmente na quantidade de publicações. Este cenário é parcialmente explicado pelo aumento expressivo no número de artigos em periódicos internacionais, o que remete a uma reflexão sobre qual é o estado da produção científica nacional (TANI, 2014).

Até a década de 1970, as pesquisas em Ciências do Esporte no Brasil norteavam-se, principalmente, por influência das ciências biológicas, relacionadas à fisiologia e à medicina esportiva (BRACHT, 1993). A partir de 1980, o avanço científico e a propagação do conhecimento direcionaram um conjunto de investigadores a indagar e a compreender o fenômeno esportivo na sua pluralidade e abrangência, abordando-o nos mais diversos campos científicos e práticos. Foram nesses pressupostos que houve uma transformação nessas concepções, verificando um crescimento no número de pesquisas cujas temáticas são influenciadas pelas ciências humanas e sociais, dentre elas, a pedagogia do esporte (RUFINO; DARIDO, 2011).

De fato, estas influências das ciências humanas contribuíram para a formação de um campo de estudos sobre os processos pedagógicos relacionados ao esporte. Nesse sentido, a pedagogia do esporte contribui como uma área de estudos relevante para a discussão de princípios e meios de ensino de modalidades esportivas, assim como os objetivos e sentidos de se ensinar. Diversos estudos dessa temática, ao proporem modelos de ensino, se preocupam em organizar, sistematizar, aplicar e avaliar procedimentos pedagógicos, objetivando desenvolver praticantes inteligentes, capazes de perceber e solucionar os problemas oriundos da prática (MACHADO; GALLATI; PAES, 2015; MENEZES; DOS REIS; TOURINHO FILHO, 2015; THOMAZ DE AQUINO et al., 2015).

Desse modo, o desenvolvimento dos processos pedagógicos que envolvem o esporte tem sido influenciado por questões e abordagens de diferentes correntes, das quais se pode destacar a perspectiva tecnicista e global para o ensino e treinamento das modalidades esportivas individuais e dos Jogos Esportivos Coletivos (JEC). De modo geral, a perspectiva tecnicista, centrada no desenvolvimento técnico de modo desvinculado da tática, enfatiza o aprendizado em partes com base na repetição de movimentos. Por outro lado, a perspectiva global, centrada em jogos, prioriza o desenvolvimento concomitante do aspecto táticotécnico, ou seja, essa corrente prioriza a resolução de problemas por parte dos participantes (GARGANTA, 1998; MENEZES; MARQUES; NUNOMURA, 2014).

Percebe-se que os JEC constituem-se de sistemas abertos (também complexos, imprevisíveis e adaptativos) caracterizados pela dinâmica de redução/aumento da incerteza e mútua vantagem de uma equipe sobre a outra. Tais fatores perturbam constantemente os padrões de interação e produzem vários graus de desorganização interna, fazendo com que a dinâmica de uma equipe oscile entre a estabilidade e a instabilidade (CORREA et al., 2012). Desse modo, o problema fundamental que se coloca ao praticante é de natureza estratégico-tática, o que indica uma forte preocupação das pesquisas atuais sobre os JEC e os aspectos relacionados à percepção, tomada de decisão e ação (CASANOVA et al., 2012; WILLIAMS et al., 2012).

Em um estudo de revisão acerca da produção científica em pedagogia do esporte no Brasil, os autores verificaram que dentre as categorias abordadas, os JEC correspondem a $27 \%$ das publicações, sendo o principal objeto desta área de estudo. Esta predominância 
é justificada devido ao próprio contexto de interligações possíveis, como a interação entre os jogadores e equipes. Neste cenário apenas $4 \%$ dos artigos sobre pedagogia do esporte abordam a temática tática/análise de jogo, uma porcentagem considerada pequena frente às inúmeras possibilidades de estudos com esses propósitos (RUFINO; DARIDO, 2011) e sua importância frente aos processos pedagógicos que envolvem os JEC (GARGANTA, 1998).

Oito anos após tal estudo (que abordou publicações entre 2000 e 2009), considerando uma tendência de crescimento do número de pesquisas em pedagogia do esporte sugerida pelos autores (RUFINO; DARIDO, 2011), é possível questionar: como se dá o cenário quantitativo e qualitativo das pesquisas sobre aspectos tático-técnicos dos JEC publicadas em periódicos brasileiros da área de Educação Física e Esporte entre os anos de 2000 a 2015? Quais são os subtemas que compõem esse tópico de estudo nesta esfera analisada? Qual é a frequência com que os periódicos da área de Educação Física e Esporte abordam este tema e suas tendências em termos de objetos de pesquisa?

Para responder a essas indagações, o objetivo do presente estudo foi analisar a produção científica referente aos aspectos tático-técnicos nos JEC publicada em periódicos brasileiros entre 2000 e 2015. De maneira específica, buscou-se primeiramente a quantificação das publicações sobre esse tema e, posteriormente, classificação dos manuscritos em categorias, discutindo suas contribuições para as investigações sobre essa temática no Brasil.

\section{METODOLOGIA}

A presente pesquisa refere-se a uma revisão sistemática, baseada em uma busca no banco de dados online de periódicos brasileiros da área de Educação Física e Esporte, entre os meses de novembro a dezembro de 2015, indexados nas bases de dados Bireme, SCOPUS, Latindex, Lilacs, Redalyc e Scielo. Foram consideradas as 14 revistas emergentes: Motrivivência (edições: 2000-2015); Arquivos em Movimento (2008-2015); Revista Brasileira de Ciência e Movimento (edições: 2000-2015); Revista Brasileira de Ciências do Esporte (edições: 20002015); Revista Brasileira de Cineantropometria e Desempenho Humano (2000-2015); Revista Brasileira de Educação Física e Esporte (edições: 2004-2015); Revista Brasileira de Futsal e Futebol (edições: 2009-2015); Conexões (edições: 2000-2015); Revista da Educação Física da UEM (edições: 2000-2015); Revista Mackenzie de Educação Física e Esporte (edições: 2002-2015); Motriz (edições: 2000-2015); Movimento (edições: 2000-2015); Pensar a Prática (edições: 2000-2015), Revista Brasileira de Medicina do Esporte (edição: 2000-2015).

\subsection{Coleta dos dados}

A pesquisa foi realizada na base de dados de cada revista supracitada ${ }^{1}$, utilizando os descritores: tática, táticas, tático, táticos, técnica-tática, técnico-tático, jogos esportivos coletivos, modalidades esportivas coletivas; e seus respectivos descritores em inglês: tactic, tactics, tactical, technical, team sports. Os artigos que apresentaram uma ou mais palavras-chave no título e/ou no resumo e/ou nas palavras-chave e/ou no corpo dos textos foram selecionados. Consideraram-se tanto artigos de revisão quanto estudos de campo. Foram considerados dois critérios de inclusão: 1) ser publicado entre 2000 e 2015; 2) tratar unicamente de JEC. Tal recorte temporal foi definido por possibilitar um panorama atual de pesquisa nesta área. Desta forma, o número total de artigos

1 A busca dos artigos publicados na Revista Brasileira de Medicina do Esporte foi realizada na base Scielo, em função da revista disponibilizar suas publicações apenas através deste meio até o ano de 2014. A partir de 2015, foi realizada a busca no banco de dados online no site da revista. 
considerados para análise foi 335 , os quais foram lidos na íntegra para posterior análise qualitativa. Dois pesquisadores realizaram separadamente a busca da literatura para avaliar o risco de viés, conforme orientações do PRISMA (Preferred Reporting Items for Systematic Reviews and MetaAnalyses) (LIBERATI et al., 2009). O acordo interavaliador foi avaliado pelo coeficiente kappa de Cohen (k), e a taxa de concordância foi $k=0,92$, classificada como perfeita².

Após a quantificação do número de artigos consoante a cada revista, houve a sua qualificação por meio de análise temática, assim como em outros estudos similares (NEBREDA et al., 2015; RUFINO; DARIDO, 2011). A partir desta, foram propostas as seguintes categorias (Quadro 1): Análise do desempenho tático-técnico; Metodologias de ensino; Análise do desempenho energético-funcional; Formação de treinadores; Formação de atletas; Outros. Posteriormente, foi realizada a quantificação referente à modalidade coletiva analisada (por exemplo, futebol, futsal, voleibol, basquetebol, entre outros) e a faixa etária dos participantes (por exemplo, crianças e jovens $\leq 24$ anos, adultos $>24$ anos). Vale ressaltar que um artigo poderia se enquadrar em mais de uma categoria temática, assim como modalidade esportiva coletiva e faixa etária.

\subsection{Análise e apresentação dos dados}

Foi realizada estatística descritiva, com análises de frequência e porcentagem dos resultados obtidos. Os resultados foram discutidos de acordo com a produção científica no período temporal analisado, nos periódicos, nas categorias temáticas, nas modalidades esportivas e na faixa etária dos participantes.

Quadro 1 - Definições das categorias temáticas emergentes na revisão sistemática.

\begin{tabular}{|l|l|}
\hline Categorias Temáticas & \multicolumn{1}{c|}{ Definições } \\
\hline $\begin{array}{l}\text { Análise do desempenho } \\
\text { tático-técnico }\end{array}$ & $\begin{array}{l}\text { Artigos que objetivaram a discussão e/ou desenvolvimento e/ou aplicação de } \\
\text { instrumentos de análise tático-técnica nos JEC (por exemplo, avaliação do } \\
\text { conhecimento tático, registro do número de passes bem/malsucedidos). }\end{array}$ \\
\hline Metodologias de ensino & $\begin{array}{l}\text { Artigos que discutiram os princípios pedagógicos de ensino nos JEC (por exemplo, } \\
\text { analítico-sintético, global-funcional). }\end{array}$ \\
\hline $\begin{array}{l}\text { Análise do desempenho } \\
\text { energético-funcional }\end{array}$ & $\begin{array}{l}\text { Artigos que analisaram o desempenho físico de praticantes de JEC (por exemplo, } \\
\text { avaliações da resistência, força e velocidade). }\end{array}$ \\
\hline $\begin{array}{l}\text { Formação de } \\
\text { treinadores }\end{array}$ & $\begin{array}{l}\text { Artigos que investigaram as disciplinas e conteúdos relevantes na formação de } \\
\text { professores e treinadores de JEC. }\end{array}$ \\
\hline Formação de atletas & $\begin{array}{l}\text { Artigos que examinaram a concepção de treinadores e de jogadores acerca das } \\
\text { etapas e variáveis mais importantes na formação de praticantes de JEC. }\end{array}$ \\
\hline Outros & $\begin{array}{l}\text { Artigos que abordaram outros aspectos relacionados aos JEC, tais como: avaliação } \\
\text { do estresse, aproveitamento de pontos das equipes durante as competições, valores } \\
\text { humanos. }\end{array}$ \\
\hline
\end{tabular}

Nota: JEC: Jogos Esportivos Coletivos. Fonte: Dados da pesquisa

\section{RESULTADOS}

\subsection{Análise quantitativa}

Os resultados referentes ao número de artigos publicados por ano estão apresentados na Figura 1. Verifica-se um aumento progressivo na quantidade de artigos publicados sobre 0 aspecto tático-técnico nos JEC com o passar dos anos, principalmente a partir de 2009, com uma variação entre 2010 e 2014, atingindo o auge em 2015.

2 Foi utilizado o software IBM SPSS Statistics (versão 22.0 - IBM Corporation囚) para análise do coeficiente de kappa de Cohen (k). 
Figura 1 - Número de artigos relacionados ao aspecto tático-técnico nos jogos esportivos coletivos de 2000 a 2015 publicados em periódicos brasileiros.

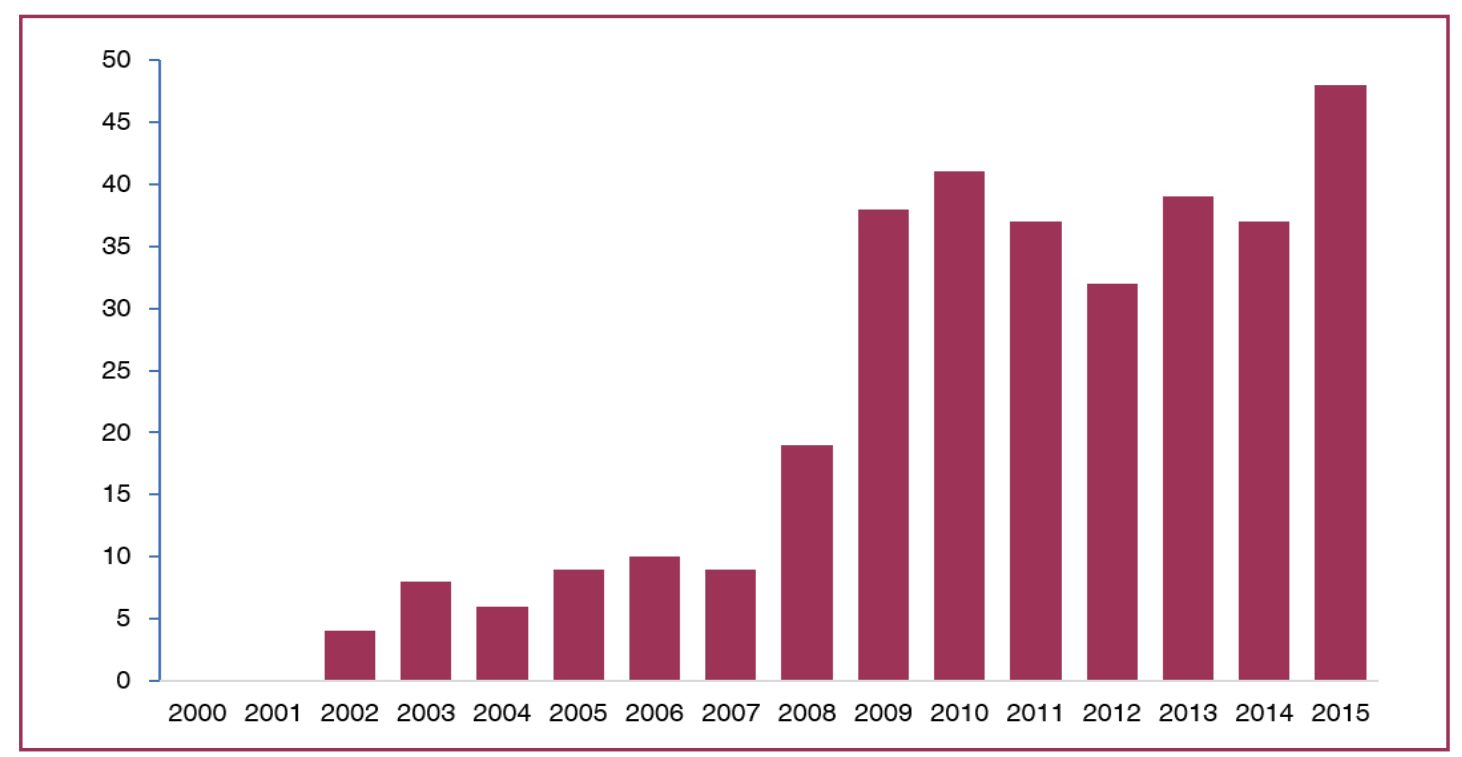

Fonte: Os autores.

A Tabela 1 indica o número de artigos por periódicos a cada ano. Foi encontrada uma média de 23,9 artigos publicados por periódico (335 - n- total de artigos / $14-\mathrm{n}^{0}$ total de revistas) e 20,9 artigos publicados por ano (335 / 16 - no total de anos analisados). Ademais, quando dividido o período analisado em três fases, A - 2000-2005 (26 artigos), B - 2006-2010 (116 artigos), $C$ - 2011-2015 (193 artigos) observa-se que a fase $C$ representa o período com maior frequência de aparição de artigos. De forma ainda a destacar na Tabela 1, verifica-se que a revista Motriz apresentou maior número de publicações $(28,4 \%)$.

Tabela 1 - Número total de artigos em cada um dos periódicos analisados entre 2000 e 2015.

\begin{tabular}{|c|c|c|c|c|c|c|c|c|c|c|c|c|c|c|c|c|c|}
\hline Ano/Periódico & ర్రి & ర్ & ণั & ஜั่ & ठั & นั้ & ஜั. & స్ & ర్ & ठั. & 음 & $\bar{c}$ & ัั & న & 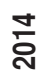 & ำ & $\begin{array}{c}\text { Total }(\%) \\
\text { (por periódico) }\end{array}$ \\
\hline Motriz & 0 & 0 & 2 & 5 & 1 & 1 & 2 & 5 & 2 & 15 & 15 & 11 & 9 & 12 & 8 & 7 & $95(28,4)$ \\
\hline RBEFE & 0 & 0 & 0 & 0 & 4 & 4 & 7 & 2 & 4 & 5 & 8 & 10 & 8 & 3 & 3 & 8 & $66(19,7)$ \\
\hline RBFF & 0 & 0 & 0 & 0 & 0 & 0 & 0 & 0 & 0 & 4 & 4 & 4 & 4 & 9 & 14 & 16 & $55(16,4)$ \\
\hline Pensar a Prática & 0 & 0 & 0 & 0 & 0 & 0 & 0 & 0 & 4 & 5 & 2 & 1 & 1 & 3 & 1 & 0 & $17(5,1)$ \\
\hline Conexões & 0 & 0 & 0 & 1 & 0 & 1 & 0 & 1 & 3 & 1 & 2 & 0 & 4 & 2 & 1 & 1 & $17(5,1)$ \\
\hline REF & 0 & 0 & 0 & 1 & 1 & 0 & 0 & 0 & 0 & 2 & 2 & 0 & 1 & 4 & 3 & 2 & $16(4,8)$ \\
\hline $\mathrm{RBCM}$ & 0 & 0 & 1 & 0 & 0 & 0 & 0 & 0 & 1 & 0 & 2 & 2 & 1 & 2 & 2 & 4 & $15(4,5)$ \\
\hline RMEFE & 0 & 0 & 0 & 0 & 0 & 1 & 0 & 0 & 4 & 0 & 5 & 1 & 0 & 0 & 2 & 0 & $13(3,9)$ \\
\hline RBCE & 0 & 0 & 1 & 0 & 0 & 0 & 0 & 0 & 0 & 0 & 0 & 2 & 0 & 0 & 2 & 5 & $10(3,0)$ \\
\hline $\mathrm{RBCDH}$ & 0 & 0 & 0 & 0 & 0 & 2 & 0 & 1 & 0 & 2 & 0 & 2 & 0 & 1 & 0 & 1 & $9(2,7)$ \\
\hline Movimento & 0 & 0 & 0 & 0 & 0 & 0 & 0 & 0 & 0 & 2 & 0 & 2 & 1 & 1 & 1 & 2 & $9(2,7)$ \\
\hline RBME & 0 & 0 & 0 & 0 & 0 & 0 & 1 & 0 & 0 & 1 & 0 & 1 & 1 & 1 & 0 & 1 & $6(1,8)$ \\
\hline AM & 0 & 0 & 0 & 0 & 0 & 0 & 0 & 0 & 1 & 1 & 0 & 0 & 1 & 1 & 0 & 1 & $5(1,5)$ \\
\hline Motrivivência & 0 & 0 & 0 & 0 & 0 & 0 & 0 & 0 & 0 & 0 & 0 & 1 & 1 & 0 & 0 & 0 & $2(0,6)$ \\
\hline Total (por ano) & 0 & 0 & 4 & 7 & 6 & 9 & 10 & 9 & 19 & 38 & 40 & 37 & 32 & 39 & 37 & 48 & $335(100)$ \\
\hline
\end{tabular}

Nota: RBEFE: Revista Brasileira de Educação Física e Esporte; RBFF: Revista Brasileira de Futsal e Futebol; REF: Revista da Educação Física da UEM; RBCM: Revista Brasileira de Ciência e Movimento; RMEFE: Revista Mackenzie de Educação Física e Esporte; RBCE: Revista Brasileira de Ciência do Esporte; RBCDH Revista Brasileira de Cineantropometria e Desempenho Humano; RBME: Revista Brasileira de Medicina do Esporte; AM: Arquivos em Movimento. 


\subsection{Análise qualitativa}

$\mathrm{Na}$ Figura 2, encontram-se os resultados referentes ao número total de artigos publicados em cada categoria temática. Observa-se que a categoria mais investigada corresponde à Análise do desempenho tático-técnico, seguida de Metodologias de ensino, Análise do desempenho energético-funcional, Formação de treinadores, Formação de atletas e Outros (por exemplo, avaliação do estresse, aproveitamento de pontos das equipes durante as competições e identificação dos valores humanos em praticantes de JEC).

Figura 2 - Número total de artigos, por categoria temática, publicados nos periódicos brasileiros analisados.

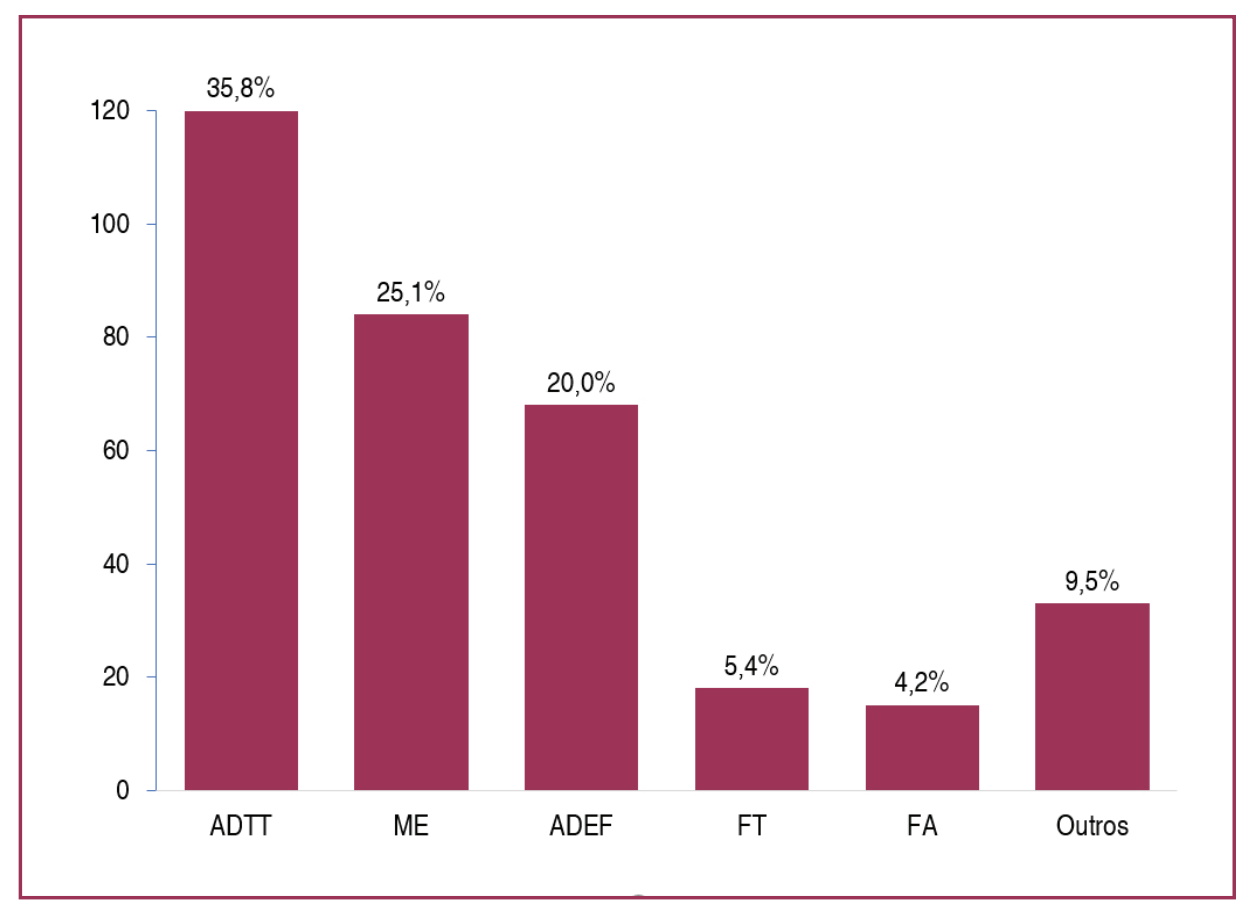

Nota: ADTT: Análise do desempenho tático-técnico; ME: Metodologias de ensino; ADEF: Análise do desempenho energético-funcional; FT: Formação de Treinadores; FA: Formação de Atletas.

Fonte: Os autores.

Na Tabela 2 estão expostos os resultados do número total de artigos publicados para cada categoria temática de cada revista analisada. Destaca-se que a Revista Brasileira de Futsal e Futebol (RBFF) apresenta o maior número de publicações na temática Análise do desempenho tático-técnico (32 artigos), seguida da Motriz e Revista Brasileira de Educação Física e Esporte (24 artigos em cada). Para as temáticas Metodologias de ensino e Análise do desempenho energético-funcional, a Motriz apresentou maior número de publicações (21 e 28 artigos respectivamente). Em relação ao tema Formação de treinadores, observa-se que a Revista Brasileira de Educação Física e Esporte lidera o quadro de publicações (seis artigos). Finalmente, a Motriz também demonstra o maior número de publicações na temática Formação de atletas (oito artigos). Encontra-se com destaque em negrito na Tabela 2 os periódicos com maior número de artigos em cada temática.

A Figura 3 contempla o número total de artigos publicados em cada uma das modalidades esportivas encontradas. Verifica-se que a modalidade esportiva coletiva com maior frequência de ocorrência é o futebol $(33,1 \%)$, logo em seguida, o futsal $(17,6 \%)$, o voleibol $(13,4 \%)$, os JEC (12,5\%) abordados de maneira geral, não especificando as modalidades, o basquetebol 
$(9,0 \%)$, o handebol $(7,5 \%)$, o voleibol de areia (1,5\%), o rúgbi, rúgbi em cadeira de rodas e futebol adaptado ( $0,9 \%$ cada), o hóquei, goalball e polo aquático ( $0,6 \%$ cada), o futebol de areia, voleibol sentado e basquetebol em cadeira de rodas $(0,3 \%$ cada).

Tabela 2 - Número total de artigos em cada um dos periódicos analisados para cada categoria temática.

\begin{tabular}{lccccccc}
\hline $\begin{array}{l}\text { Categoria temátical } \\
\text { Periódico }\end{array}$ & ADTT & ME & ADEF & FT & FA & Outros & $\begin{array}{c}\text { Total (\%) } \\
\text { (por periódico) }\end{array}$ \\
\hline Motriz & 24 & 21 & 28 & 5 & 8 & 9 & $95(28,4)$ \\
RBEFE & 24 & 10 & 14 & 6 & 2 & 10 & $66(19,7)$ \\
RBFF & 32 & 9 & 6 & 2 & 1 & 5 & $55(16,4)$ \\
Pensar a Prática & 3 & 11 & 2 & 1 & 0 & 0 & $17(5,1)$ \\
Conexões & 7 & 5 & 2 & 1 & 1 & 1 & $17(5,1)$ \\
REF & 10 & 3 & 1 & 0 & 1 & 1 & $16(4,8)$ \\
RBCM & 5 & 8 & 1 & 0 & 0 & 1 & $15(4,5)$ \\
RMEFE & 3 & 4 & 3 & 1 & 1 & 1 & $13(3,9)$ \\
RBCE & 4 & 4 & 1 & 0 & 0 & 1 & $10(3,0)$ \\
RBCDH & 3 & 1 & 4 & 0 & 0 & 1 & $9(2,7)$ \\
Movimento & 2 & 7 & 0 & 0 & 0 & 0 & $9(2,7)$ \\
RBME & 0 & 0 & 4 & 0 & 0 & 2 & $6(1,8)$ \\
AM & 3 & 1 & 1 & 0 & 0 & 0 & $5(1,5)$ \\
Motrivivência & 0 & 0 & 0 & 2 & 0 & 0 & $2(0,6)$ \\
\hline Total (por categoria) & $\mathbf{1 2 0}$ & $\mathbf{8 4}$ & $\mathbf{6 7}$ & $\mathbf{1 8}$ & $\mathbf{1 4}$ & $\mathbf{3 2}$ & $\mathbf{3 3 5}(100)$ \\
\hline
\end{tabular}

Nota: RBEFE: Revista Brasileira de Educação Física e Esporte; RBFF: Revista Brasileira de Futsal e Futebol; REF: Revista da Educação Física da UEM; RBCM: Revista Brasileira de Ciência e Movimento; RMEFE: Revista Mackenzie de Educação Física e Esporte; RBCE: Revista Brasileira de Ciência do Esporte; RBCDH Revista Brasileira de Cineantropometria e Desempenho Humano; RBME: Revista Brasileira de Medicina do Esporte; AM: Arquivos em Movimento; ADTT: Análise do desempenho tático-técnico; ME: Metodologias de ensino; ADEF: Análise do desempenho energético-funcional; FT: Formação de Treinadores; FA: Formação de Atletas.

Fonte: Os autores.

Figura 3. Número total de artigos referentes às modalidades esportivas encontradas nos periódicos analisados.

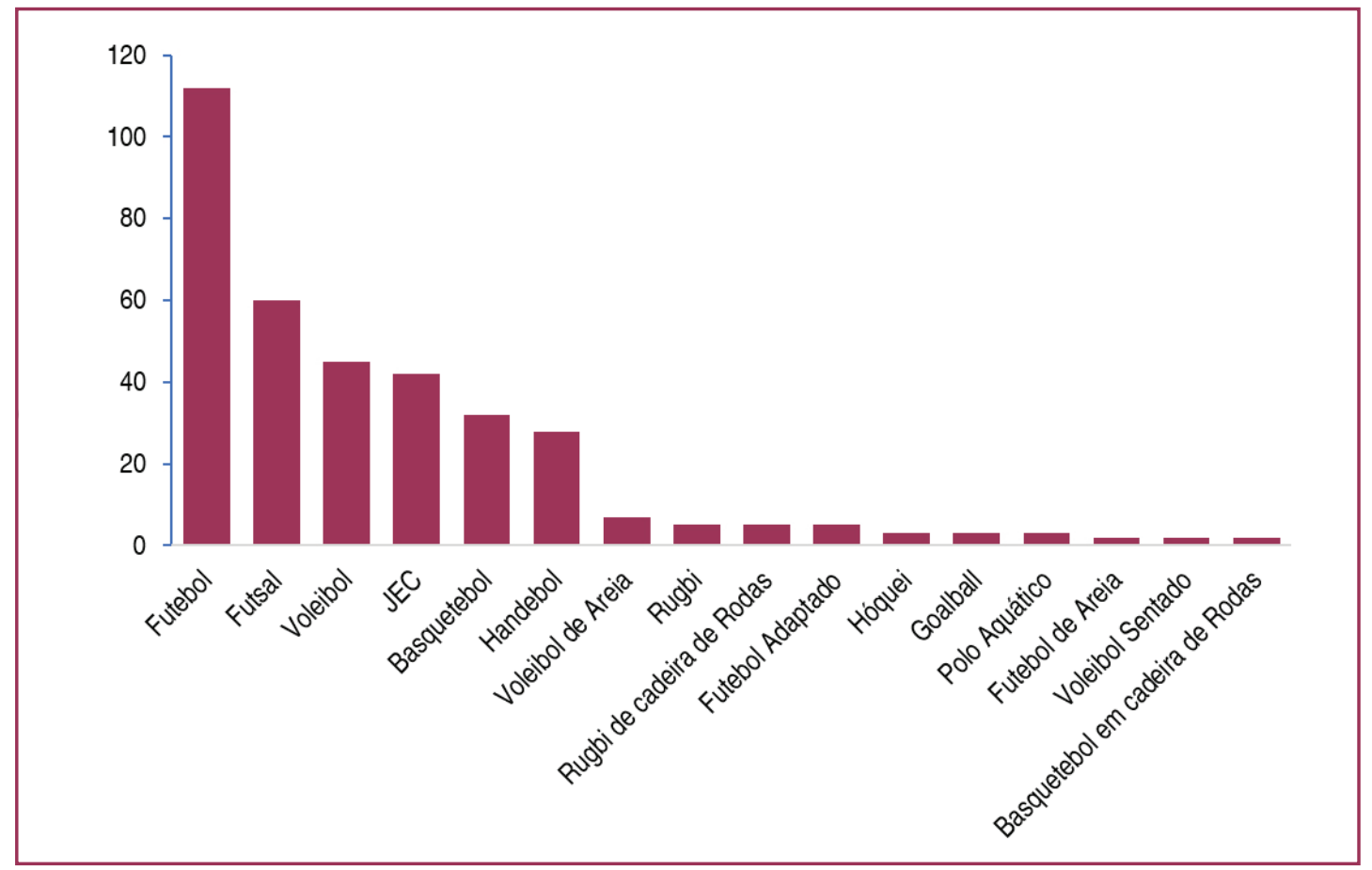

Fonte: Os autores. 
Conforme se pode constatar na Figura 3, apenas 3,0\% dos artigos analisados abordam modalidades esportivas coletivas adaptadas: rúgbi em cadeira de rodas, futebol adaptado, goalball, voleibol sentado e basquetebol em cadeira de rodas.

Quando analisada a faixa etária dos participantes para cada artigo selecionado (no caso das pesquisas de campo), foi observado que 55,0\% dos artigos se dedicam a estudos sobre a população adulta, enquanto que $45,0 \%$ se reportam a crianças e jovens.

\section{DISCUSSÃO}

O objetivo do presente estudo foi analisar a produção científica referente aos aspectos tático-técnicos nos JEC publicada em periódicos brasileiros entre 2000 e 2015. Não foram encontrados demais estudos que tenham analisado a produção científica sobre 0 aspecto tático-técnico nos JEC nos periódicos brasileiros analisados. Os principais achados consistem na diferença absoluta entre o número total de artigos por ano em relação às categorias temáticas e as modalidades esportivas coletivas encontradas. É possível observar que a maior frequência de publicações encontra-se entre as temáticas Análise do desempenho táticotécnico e Metodologias de ensino, com 60,3\% das publicações nos periódicos analisados. Além disso, das 16 modalidades exibidas nos artigos, o futebol e o futsal contemplam 50,7\% das publicações, o que corrobora a grande identificação cultural do brasileiro com tais modalidades (FREIRE, 2003). Entretanto, esse número é parcialmente explicado pelo grande número de publicações na Revista Brasileira de Futsal e Futebol (55 artigos), a qual se dedica especialmente a tais modalidades.

Ademais, dentro do cenário brasileiro, o futebol é um esporte com grande interesse científico e prático, devido ao elevado número de participantes e suas representações históricas e culturais (ARGOLO, 2015), englobando tanto as vertentes do esporte em âmbito lúdico como profissionalizante (MEDINA, 2009). Tais fatores podem explicar a maior produção científica brasileira sobre o futebol, assim como o futsal, modalidade esportiva com fortes vínculos culturais com o futebol (CAVICHIOLLI et al., 2011).

Voleibol, basquetebol e handebol também foram modalidades esportivas com alta frequência de aparição (13,4\%, 9,0\% e 7,5\% respectivamente), de modo a atribuir esse resultado ao crescente interesse de pesquisadores pela compreensão global, ou seja, dos componentes físicos e tático-técnicos, das principais modalidades praticadas no Brasil (isto é, futebol, futsal, voleibol, handebol, basquetebol) (DE ROSE JUNIOR, 2006). Adicionalmente, uma parte das publicações (12,5\%) direcionou suas discussões para os JEC de maneira geral, não especificando uma modalidade em especial.

As modalidades esportivas coletivas para pessoas com deficiência (isto é, goalball, futebol adaptado, voleibol sentado, rúgbi em cadeira de rodas, basquetebol em cadeira de rodas) aparecem com baixo número de publicações. Juntas somaram 3,0\% de todas as publicações, representando uma carência científica dessa temática no cenário brasileiro. Considerando uma nova perspectiva de educação para o século XXI, baseada na inclusão, não se espera a dissociação e discrepância de valorização entre a Educação Física e Esporte de suas práticas adaptadas (COSTA; SOUSA, 2004; DORÉ et al., 1997).

Os resultados encontrados no presente estudo, no que se refere ao número total de artigos por ano de publicação, apresentam ausência de publicações nos anos de 2000 
e 2001. Posteriormente, a partir do ano de 2002, é verificado um aparente crescimento com o passar dos anos, com alterações substanciais na progressão do quadro de publicações nos últimos anos, nomeadamente em 2015, especialmente a partir de 2009. Esse dado se faz particularmente interessante, pois coloca os resultados do presente estudo em rota de complementação ao estudo anterior de Rufino e Darido (2011), que encerrou sua análise sobre artigos ligados à pedagogia do esporte no ano de 2009 e apontou, até aquele momento, uma pequena incidência de trabalhos sobre aspectos tático-técnicos dos JEC. Os dados do presente estudo sugerem que esse cenário se modificou nos últimos anos. Importa ressaltar que dentre as revistas investigadas, quatro iniciaram suas edições após 0 ano 2000, fato que pode ter contribuído para o aumento gradativo das publicações com o passar dos anos.

Os JEC se configuram como sistemas abertos, aleatórios e imprevisíveis (MENEZES, 2012) que geram aos participantes um constante enfrentamento de natureza tática (COSTA et al., 2010; GARCÍA, 2008; GARCÍA; RODRÍGUEZ; GARZÓN, 2011; GRAÇA; MESQUITA, 2007). Dessa forma, verifica-se uma tendência de valorização das temáticas Análise do desempenho tático-técnico e Metodologias de ensino para uma compreensão sistêmica. Ou seja, considerando os JEC como fenômeno complexo e indissociável, com uma abordagem multifatorial e holística, o aspecto tático-técnico e seus meios de ensino têm grande importância nos processos pedagógicos e nas avaliações das modalidades esportivas coletivas (BAYER, 1994; DAOLIO; MARQUES, 2003; GARGANTA, 1998; MENEZES; MARQUES; NUNOMURA, 2014; THOMAZ DE AQUINO et al., 2015). Essa tendência corrobora estudos sobre a produção científica internacional na área em questão (COUREL-IBÁÑEZ; MCROBERT; TORO; VÉLEZ, 2017; GONZÁLEZ-VÍLLORA; SERRA-OLIVARES; PASTOR-VICEDO; COSTA, 2015; SERRAOLIVARES; CLEMENTE; GONZÁLEZ-VÍLLORA, 2016; SILVA; MARCELINO; LACERDA; JOÃO, 2016).

Quando analisado o conteúdo dos estudos de campo enquadrados na temática Análise do desempenho tático-técnico, é observado que 57,7\% dos artigos reportam acerca da avaliação das ações tático-técnicas em contexto real de disputa (por exemplo, passes, desarmes, finalizações), igualmente encontrado em estudos recentes (CANAN; MENDES; SILVA, 2015; SANTOS; MORAES; COSTA, 2015). Ou seja, uma análise das ações táticotécnicas considerando sua concepção eficaz e adaptativa (isto é, pautando no resultado da ação e não na forma de execução do gesto motor). Adicionalmente, 42,3\% dos artigos objetivaram o desenvolvimento e/ou utilização de avaliações centradas no conhecimento tático, tanto declarativo, quanto processual. O primeiro consiste na demonstração de forma verbal e/ou escrita do "que fazer" em determinada situação do jogo. Já o segundo representa a capacidade do praticante em operacionalizar a ação, ou seja, "onde", "quando" e as "razões do que fazer" em contexto real de disputa (GRECO et al., 2015).

Na temática Metodologias de ensino, 66,4\% dos artigos publicados apresentam e/ ou discutem os processos pedagógicos com base na concepção holística, que considera os componentes complexos e dinâmicos do jogo (MESQUITA; PEREIRA; GRAÇA, 2009). Em contrapartida, apenas $33,6 \%$ dos artigos desta temática centraram em uma perspectiva meramente técnica, de modo que as análises não abordaram questões táticas (por exemplo, MATTA et al., 2014). Esses dados novamente corroboram certa tendência centrada na visão sistêmica e global de ensino dos JEC no Brasil (RUFINO; DARIDO, 2011). Essas tendências emergentes podem ser fundamentadas por propostas metodológicas sugeridas na literatura 
internacional, tais como (THOMAZ DE AQUINO et al., 2015): Global Funcional - Alemanha (DIETRICH; DÜRRWÄCHTER; SCHALLER, et al., 1984), Teaching Games for Understanding - Inglaterra, Game Sense- Austrália, Game Concept Approach-Singapura, Tactical Approach - EUA, Tactical Decision Making Approach - França (GRAÇA; MESQUITA, 2007).

A terceira categoria temática mais presente nas publicações refere-se à Análise do desempenho energético-funcional. Dentro dela, os artigos procuraram apresentar e discutir resultados referentes aos meios de avaliações, monitoramento e planejamento do treinamento esportivo, levando em consideração as variáveis fisiológicas (por exemplo, concentração de lactato, frequência cardíaca) e motoras (por exemplo, força, velocidade, resistência) (FREITAS; MILOSKI; BARA FILHO, 2015). Embora essa categoria de trabalhos valorize a preparação e aptidão física de esportistas, de certo modo, sem um vínculo íntimo com abordagens táticotécnicas, é possível encontrar na literatura justificativas sobre a relação estreita entre tais tópicos (MEYLAN; MALATESTA, 2009), algo reforçado pelo considerável número de estudos sobre essa temática a partir de uma pesquisa com palavras-chave ligadas apenas a aspectos tático-técnicos.

Uma das contribuições da pedagogia do esporte compreende a formação de profissionais envolvidos nos processos pedagógicos, sejam eles no planejamento, organização, gestão ou execução (MENEZES; MARQUES; NUNOMURA, 2014; REVERDITO; SCAGLIA, 2009). Observou-se no presente estudo baixa aparição das temáticas Formação de treinadores e Formação de atletas em relação ao número de publicações (5,4 e 4,2\% respectivamente). Os artigos enquadrados nessa categoria abordam algumas questões principais, como: os princípios pedagógicos e métodos de ensino utilizados sobre JEC, as relações entre treinadorespraticantes, caracterização da carreira esportiva dos atletas (por exemplo, escolaridade, contexto sociofamiliar, iniciação) e indicadores de acesso à excelência no esporte. De maneira geral, destaca-se a importância atribuída aos estímulos e propostas de jogo como ferramenta pedagógica nos processos de ensino-aprendizagem-treinamento, visando à compreensão da complexidade dos JEC.

Os resultados encontrados e as discussões estabelecidas procuram auxiliar a construção de um recorte sobre o panorama de pesquisas publicadas em periódicos brasileiros da área de Educação Física e Esporte, entre os anos de 2000 a 2015, possibilitando verificar as temáticas e as modalidades esportivas mais abordadas em cada periódico, auxiliando o direcionamento de novas linhas/propostas/problemas de pesquisas, assim como futuros autores na escolha de periódicos para divulgação de seus resultados e reflexões sobre o tema. Entretanto, o presente estudo apresenta limitações ligadas à restrição à busca apenas em periódicos brasileiros. Futuras pesquisas podem ampliar a investigação em periódicos internacionais, assim como em outros meios de divulgação científica.

\section{CONSIDERAÇÕES FINAIS}

O auge das publicações acerca do aspecto tático-técnico nas modalidades esportivas encontradas no Brasil ocorreu entre os anos de 2009 a 2015. Em destaque, observa-se que a Motriz, a Revista Brasileira de Educação Física e Esporte e a Revista Brasileira de Futsal e Futebol contribuíram substancialmente para o elevado número de publicações nesse período $(95,66,55$ artigos, respectivamente). Dentro das categorias estipuladas por meio da análise 
temática, a Análise do desempenho tático-técnico, juntamente com a Metodologia de ensino, representa $60,9 \%$ das publicações, o que evidencia uma valorização desses temas sobre os demais. Discute-se essa valorização ao recente entendimento dos JEC pelos pesquisadores e treinadores esportivos com ênfase a uma abordagem multifatorial e holística. Portanto, verificase por meio dessa compreensão uma gama de possibilidades de futuras pesquisas ligadas a investigações sobre diferentes aspectos dos JEC (tais como formação de treinadores e atletas, modalidades esportivas coletivas adaptadas), tanto em periódicos, quanto em outros meios de divulgação científica.

\section{REFERÊNCIAS}

ARGOLO, Januária Salles. Análise temporal dos gols no futebol feminino nos jogos olímpicos de Londres 2012. Revista Brasileira de Futsal e Futebol, v.7, n.24, p.191-194, 2015. Supl. 1.

BAYER, Claude. 0 ensino dos desportos coletivos. Lisboa: Dinalivro, 1994.

BRACHT, Valter. Educação Física/ciências do esporte: que ciência é essa? Revista Brasileira de Ciências do Esporte, v. 14, n. 3, p. 111-118, 1993.

CANAN, Felipe; MENDES, José Carlos; DA SILVA, Rogério Vaz. Análise estatística no basquetebol de base: perfil do Campeonato Paranaense de Basquetebol masculino Sub-17. Revista Brasileira de Educação Física e Esporte, v.29, n.2, p.289-302, abr.jun. 2015.

CASANOVA, Filipe et al. Expertise and perceptual-cognitive performance in soccer. Revista Portuguesa de Ciências do Desporto, v.9, n.1, p.115-122, 2012.

CAVICHIOLLI, Fernando Renato et al. O processo de formação do atleta de futsal e futebol: análise etnográfica. Revista Brasileira de Educação Física e Esporte, v.25, n.4, p.631-647, out./dez. 2011.

CORREA, Umberto César et al. The game of futsal as an adaptive process. Nonlinear Dynamics, Psychology, and Life Science, v.16, n.2, p.185-203, set. 2012.

COSTA, Alberto Martins; SOUSA, Sônia Bertoni. Educação Física e Esporte adaptado: história, avanços e retrocessos em relação aos princípios da integração/inclusão e perspectivas para o século XXI. Revista Brasileira de Ciência do Esporte, v.25, n.3, p.27-42, maio 2004.

COSTA, Israel Teoldo et al. Análise do comportamento táctico de futebolistas através do teste "GR33GR": estudo de caso de uma equipa sub-11. Lecturas, Educación Física y Deportes, Buenos Aires, v. 14, n 142, 2010. Disponível em: <http://www.efdeportes.com/efd142/analise-do-comportamentotactico-de-futebolistas.htm>. Acesso em: 10 ago. 2016.

COUREL-IBÁÑEZ, Javier et al. Collective behaviour in basketball: a systematic review. International Journal of Performance Analysis in Sport, v.17, n.1-2, p.44-64, 2017.

DAOLIO, Jocimar; MARQUES, Renato Francisco Rodrigues. Relato de uma experiência de ensino do futsal para crianças de 9 a 12 anos. Motriz, v.9, n. 3, p. 169-174, 2003.

DE ROSE JUNIOR, Dante. Modalidades esportivas coletivas. Rio de Janeiro: Guanabara Koogan, 2006.

DIETRICH, Knut; DÜRRWÄCHTER, Gerhard; SCHALLER, Hans-Jürgen. Os grandes jogos: metodologia e prática. Rio de Janeiro: Ao livro técnico, 1984. 
DORÉ, Robert; WAGNER, Serge; BRUNET, Jean-Pierre. A integração escolar: os principais conceitos, os desafios e os fatores de sucesso no secundário. In: MANTOAN, Maria Teresa Eglér. A integração de pessoas com deficiência: contribuições para uma reflexão sobre o tema. São Paulo: Memnon, 1997. p. 174-183.

FREIRE, Paulo. Pedagogia da autonomia: saberes necessários à prática educativa. São Paulo: Paz e Terra, 2003.

FREITAS, Victor Hugo de; MILOSKI, Bernardo; BARA FILHO, Maurício Gattás. Monitoramento da carga interna de um período de treinamento em jogadores de voleibol. Revista Brasileira de Educação Física e Esporte, v.29, n.1, p.5-12, jan./mar. 2015.

GARCÍA, Luis Miguel García. Investigación y enseñanza técnico-táctica en el fútbol. Cultura Ciencia y Deporte, v. 9, n. 3, p. 161-168, 2008.

GARCÍA, Sandra; RODRÍGUEZ, Andrés; GARZÓN, Alexandra. Conceptualización de inteligencia táctica en fútbol: consideraciones para el desarrollo de un instrumento de evaluación en campo desde las funciones ejecutivas. Cuadernos de Psicología del Deporte, v.11, n.1, p.69-78, 2011.

GARGANTA, Júlio. Para uma teoria dos jogos desportivos colectivos. In: GRAÇA, Amândio; OLIVEIRA, José. (Orgs.) 0 ensino dos jogos desportivos. 3. ed. Porto: Universidade do Porto, 1998. p. 11-25.

GONZÁLEZ-VÍLLORA, Sixto et al. Review of the tactical evaluation tools for youth players, assessing the tactics in team sports: football. SpringerPlus, v.4, n.663, p.1-17, 2015.

GRAÇA, Amândio; MESQUITA, Isabel. A investigação sobre os modelos de ensino dos jogos desportivos. Revista Portuguesa de Ciências do Desporto, v.7, n.3, p.401-421, 2007.

GRECO, Pablo Juan et al. Evidência de validade do teste de conhecimento tático processual para orientação esportiva - TCTP:OE. Revista Brasileira de Educação Física e Esporte, v.29, n.2, p.313324, abr./jun. 2015.

LIBERATI, Alessandro et al. The PRISMA statement for reporting systematic reviews and metaanalyses of studies that evaluate health care interventions: explanation and elaboration. PLoS Medicine, v.6, n.e1000100, 2009.

MACHADO, Gisele Viola; GALATTI, Larissa Rafaela; PAES, Roberto Rodrigues. Pedagogia do esporte e projetos sociais: interlocuções sobre a prática pedagógica. Movimento, v.21, n.2, p.405418, abr.jun. 2015.

MATTA, Marcelo de Oliveira et al. Morphological and maturational predictors of technical performance in young soccer players. Motriz, v.20, n.3, p.280-285, 2014.

MEDINA, Frederico. El fútbol y la vivencia festiva de la nacionalidad. Razón y palabra, México, $n$. 69, 2009. Disponível em: <https://www.razonypalabra.org.mx>. Acesso em: 15 dez. 2015.

MENEZES, Rafael Pombo. Contribuições da concepção dos fenômenos complexos para o ensino dos esportes coletivos. Motriz, v.18, n.1, p.34-41, 2012.

MENEZES, Rafael Pombo; DOS REIS, Heloisa Helena Baldy; TOURINHO FILHO, Hugo. Ensinoaprendizagem-treinamento dos elementos técnico-táticos defensivos individuais do handebol nas categorias infantil, cadete e juvenil. Movimento, v.21, n.1, p. 261-273, jan./mar. 2015. 
MENEZES, Rafael Pombo; MARQUES, Renato Francisco Rodrigues; NUNOMURA, Myrian. Especialização esportiva precoce e o ensino dos jogos coletivos de invasão. Movimento, v.20, n.1, p.351-373, 2014.

MESQUITA, Isabel; PEREIRA, Felismina Rosa Marques; GRAÇA, Amândio Braga dos Santos. Teaching game models: research and outcomes for the practice domain. Motriz, v.15, n.4, p.944-954, 2009.

MEYLAN, Cesar; MALATESTA, Davide. Effects of in-season plyometric training within soccer practice on explosive actions of young players. Journal of Strength and Conditioning Research, v.23, n.9, p.2605-2613, dez. 2009.

NEBREDA, Xabier Martín et al. Producción científica sobre fútbol en revistas españolas de ciencias de la actividad física y del deporte. Movimento, v.21, n.3, p.659-672, jul./set. 2015.

REVERDITO, Riller Silva; SCAGLIA, Alcides José. Pedagogia do esporte: jogos coletivos de invasão. São Paulo: Phorte, 2009.

RUFINO, Luis Gustavo Bonatto; DARIDO, Suraya Cristina. A produção científica em pedagogia do esporte: análise de alguns periódicos nacionais. Conexões, v.9, n.2, p.110-132, maio/ago. 2011.

SANTOS, Rodrigo de Miranda Monteiro; MORAES, Emerson Luciano; COSTA, Israel Teoldo. Análise de padrões de transição ofensiva da Seleção Espanhola de Futebol na Copa do Mundo FIFA ${ }^{\circledR} 2000$. Revista Brasileira de Educação Física e Esporte, v.29, n.1, p.119-126, jan./mar. 2015.

SERRA-OLIVARES, Jaime; CLEMENTE, Filipe Manuel; GONZÁLEZ-VÍLLORA, Sixto. Tactical expertise assessment in youth football using representative tasks. SpringerPlus, v.5, n.1301, p.1-9, 2016.

SILVA, Miguel et al. Match analysis in Volleyball: a systematic review. Montenegrin Journal of Sports Science and Medicine, v.5, n.1, p.35-46, 2016.

TANI, G. Editoração de periódicos em Educação Física/Ciências do Esporte: dificuldades e desafios. Revista Brasileira de Ciências do Esporte, v.36, n.4, p.715-722, 2014.

THOMAZ DE AQUINO, Rodrigo Leal de Queiroz et al. Proposta de sistematização de ensino do futebol baseada em jogos: desenvolvimento do conhecimento tático em jogadores com 10 e 11 anos de idade. Motricidade, v.11, n.2, p.115-128, jun. 2015.

WILLIAMS, Andrew Mark et al. Perceptual-cognitive expertise, practice history profiles and recall performance in soccer. British Journal of Psychology, v.103, n.3, p.393-411, 2012. 
